\title{
Saúde ocupacional no século XXI: qual o papel do médico de família?
}

Avelina Pereira B. Moniz*

It is unethical and short sighted business practice to compromise the health of workers for the wealth of enterprises. Evelyn Kortum, 2007

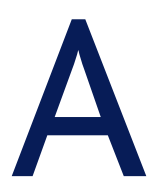
saúde dos trabalhadores é uma preocupação para quem trabalha e para quem emprega. Ao empregador cabe definir e informar acerca dos riscos potenciais do trabalho e garantir locais de trabalho seguros e saudáveis. A prestação de cuidados é da responsabilidade dos serviços de saúde ocupacional, que se organizam de acordo com a dimensão das empresas e tipologia dos riscos.

Segundo a Organização Mundial da Saúde (OMS), a principal finalidade dos serviços de saúde ocupacional é a promoção de condições laborais que garantam o mais elevado grau de qualidade de vida no trabalho, protegendo a saúde dos trabalhadores, promovendo o bem-estar físico, mental e social, prevenindo e controlando os acidentes de trabalho e as doenças através da redução das condições de risco. Este conceito garante a saúde física e mental, promove a boa adaptação ao posto de trabalho, contribuindo para a produtividade e diminuindo o absentismo.

Este interesse pela saúde dos trabalhadores, transversal às políticas de emprego e sociais, não tem sido espelhado por investimentos na área da formação e gestão nos países mais desenvolvidos. Uma revisão sistemática recente conclui que apesar da extensa publicação existente continua a existir um fosso entre a legislação, implementação e a sua transposição em procedimentos do quotidiano. ${ }^{1} \mathrm{O}$ mesmo acontece em relação à formação dos profissionais nessa área.-4

*Médica assistente graduada de Medicina Geral e Familiar, Médica do Trabalho.
Os médicos do trabalho (MT) cuidam de pessoas supostamente saudáveis e garantem que a saúde delas resiste aos riscos laborais. Acolhem o trabalhador no momento da admissão, alertam para as dificuldades e riscos específicos do posto de trabalho, incentivam hábitos saudáveis, adequam estratégias de coping. O MT segue o trabalhador no seu percurso profissional. Escuta a sua insegurança e antevê problemas com colegas e chefias. Acompanha o seu desenvolvimento profissional e pessoal e, em muitos casos, emite relatórios periciais para contacto com seguradoras e segurança social. $^{5-7}$

À medida que a complexidade aumenta nos processos de trabalho, o MT permanece um pilar de confiança. Também ensina e apoia a resiliência na mudança. Ajuda a contornar dificuldades emocionais e pessoais. Muitas vezes é o primeiro a diagnosticar a doença aguda e aí surge como advogado e conselheiro. Noutros casos apoia na reabilitação e contribui para a recolocação atempada e adequada, de modo a que o trabalhador permaneça produtivo, integrado e digno. ${ }^{8}$

É um papel com competências comuns à medicina geral e familiar (MGF), mas com especificidades próprias. ${ }^{9}$ A MT e a MGF têm semelhanças: foco na prevenção da doença e na promoção da saúde. O MT gere o doente no seu local de trabalho, promove o cumprimento das boas práticas de produção e do controlo dos factores de risco ou limites de exposição a poluentes ou outros riscos do processo de trabalho. A unidade de observação é o trabalhador, enquanto para o médico de família (MF) é o utente e/ou família. Para o MT, cada trabalhador representa um grupo alargado de colegas expostos ao mesmo risco. ${ }^{9}$

É importante aplanar as diferenças entre MT e MGF e estender pontes que permitam uma sinergia de processos para o bem-estar do utente trabalhador e de du- 
plicação de observações. Um momento muito importante de colaboração prende-se com a gestão da ausência laboral. Pode, nalguns casos, o MT sinalizar precocemente situações no âmbito da saúde mental ou da gestação de risco e a comunicação entre o MF e o médico de empresa permite encurtar ausências, promovendo uma recolocação temporária do trabalhador em situação de convalescença ou fragilidade associada à gestão de situações crónicas de saúde.

O envelhecimento da população trabalhadora, associada ao aumento da idade de reforma, coloca uma pressão acrescida sobre ambas as especialidades. É cada vez mais frequente que trabalhadores activos sejam portadores de patologias complexas, comorbilidade e multimorbilidade. É necessária colaboração para minimizar duplas coberturas ou não fornecer os cuidados necessários.

Nos anos sessenta, o emprego era para a vida, tornando relativamente fácil estabelecer um nexo de causalidade entre exposições tóxicas e local de trabalho. Actualmente assistimos a uma limitação da exposição em termos quantitativos, ${ }^{10}$ muitas das acções nocivas são explicadas pela carga de exposição; exposições minor, se perpetuadas ao longo do tempo, são igualmente nocivas, MF e MT devem estar atentos.

No início do século XXI assistiu-se a uma verdadeira revolução no mundo do trabalho. As empresas perderam dimensão. $\mathrm{O}$ trabalho perdeu características de individualidade, tornando-se polivalente, fragmentado e exercido em equipa com aumento da massa de trabalhadores exposta a alguns riscos, ditos emergentes (e.g., nanomateriais, empregos verdes, risco psicossocial). Também assistimos a elevado turnover, globalização da produção e a flexibilidade do trabalho. Muitos dos riscos são partilhados por empresas que subcontratam e que não sabem, não podem ou não querem monitorizar os riscos. Esta realidade torna muito difícil o diagnóstico e cotejo com a história natural de muitas doenças de etiologia profissional, já que o seu aparecimento pode surgir muitos anos após a exposição.

No futuro, o MT vai ocupar áreas de sobreposição no conhecimento médico, ambiental (pneumologia, dermatologia), ocupacional (toxicologia, gestão e organização do trabalho), medicina interna/MGF (diagnóstico precoce e diferencial, comorbilidades), para além de importantes conhecimentos nas áreas da qualidade e higiene e segurança.

As expectativas relacionadas com os riscos emergentes e o grande peso do risco psicossocial do sector terciário, associadas ao prolongamento das jornadas e tempos de trabalho, vão pôr em causa o edificado de pesquisa baseado em jornadas de oito horas. ${ }^{7}$

$\mathrm{O}$ aumento da esperança de vida e a crise financeira, em particular na Europa, vai obrigar a idades de reforma cada vez mais elevadas para garantir a sustentabilidade do sistema de segurança social. Tal facto criará mais pressão sobre as empresas e os MT. Já que muitas alterações crónicas podem mimetizar e interagir com o envelhecimento, esta última razão levará a uma maior visibilidade da vertente de saúde pública, obrigando a uma melhor preparação dos MT.

Em Portugal, 95\% do tecido empresarial é constituído por microempresas que empregam metade dos trabalhadores. A população laboral está envelhecida (classe modal 44 anos), concentrada no litoral e com mais de $50 \%$ localizada em Lisboa e na região Norte. Apenas $60 \%$ da população activa está empregada. ${ }^{11}$ É razoável assumir, tendo em conta a terciarização e a tendência para PME e muitos trabalhadores independentes e expatriados, que o saber da medicina do trabalho seja chamado a dirimir conflitos.

Apesar das especialidades de MGF, da saúde pública e medicina interna apresentarem um núcleo de conhecimentos médicos central para a saúde ocupacional, é necessário manter e garantir a formação especializada de MT como profissionais com validação do seu percurso profissional e que sejam confiáveis para contratação de empresas nacionais e internacionais.

Do ponto de vista específico de MGF, já tão sobrecarregado com todas as suas tarefas de promoção, prevenção, diagnóstico e seguimento de indivíduos e famílias, não é lícito esperar a sua capacitação e conhecimento para antecipar e aconselhar sobre riscos laborais de todas as pequenas empresas ou trabalhadores independentes, o que contribuirá para a desresponsabilização de empregadores que se escudarão na transferência de serviços e responsabilidades para os serviços públicos, não investindo na melhoria de condições de trabalho, nem na formação da sua força de trabalho.

Por isso, foi com satisfação que foi acolhida a alteração à Portaria no 112/2014, de 23 de maio, que regula- 
va a prestação de cuidados de saúde primários através dos ACES. Assim, pela Portaria no 121/2016 é reconhecido que "as consultas de vigilância e saúde efectuadas no SNS não poderão ser asseguradas por especialistas de MGF por se tratar de funções específicas que exigem aptidão própria obtida pela formação específica em Internato da especialidade ou reconhecimento pela Ordem dos Médicos, sendo-lhes vedada a emissão da ficha de aptidão".

Em conclusão, enquanto permanecerem desafios à economia e emprego, o paradigma demográfico não sofrer alteração, os desafios tecnológicos e científicos e a intensificação da globalização económica se associarem à incerteza relativa às políticas do trabalho e sua organização e à evolução da in(sustentabilidade) da segurança social, os profissionais de saúde ocupacional terão formação, organização e darão resposta a níveis de gravidade muitos distintos.

Os médicos de MGF são, por vezes, o primeiro contacto com o trabalhador doente; devem, por isso, informar-se acerca dos factores de risco laborais e ambientais que condicionam doença ou incapacidade. Uma boa e eficiente comunicação é desejável entre ambas as especialidades, não para descartar procedimentos, mas para garantir uma sólida base de confiança para colaboração e discussão interpares.

\section{REFERÊNCIAS BIBLIOGRÁFICAS}

1. Direcção-Geral da Saúde. Plano nacional de saúde, 2012-2016. Lisboa: DGS; 2012.

2. Danielsen TE. Changes in Europe specialist training for occupational medicine in Norway: status and trends. J Adv Res Med. 2015;2(1):31-2.

3. Greiner AC, Knebel E, editors. Health professions education: a bridge to quality [Internet]. Washington, DC: National Academies Press; 2003. ISBN 9780309087230. Available from: https://www.ncbi.nlm.nih.gov/ books/NBK221528/

4. Reetoo KN, Harrington JM, MacDonald EB. Required competencies of occupational physicians: a Delphi survey of UK customers. Occup Environ Med. 2005;62(6):406-13.

5. American Academy of Family Physicians. Recommended curriculum guidelines for family medicine residents: ocupational medicine [Internet].AAFP; 2014.Available from: http://www.aafp.org/dam/AAFP/documents/medical_education_residency/program_directors/Reprint266_ Occupational.pdf

6. Verma S, Paterson M, Medves J. Core competencies for health care professionals: what medicine, nursing, occupational therapy, and physiotherapy share. J Allied Health. 2006;35(2):109-15.

7. MacDonald E, Baranski B, Wilford J, editors. Occupational medicine in Europe: scope and competencies [Internet]. Copenhagen:World Health Organization; 2000. Available from: http://www.who.int/occupational_health/regions/en/oeheuroccmedicine.pdf?ua=1

8. Taskinen $\mathrm{H}$. Good occupational health practice: a guide for planning of follow-up of occupational health services [Internet]. Helsinki: Finnish Instituto of Occupational Health; 1997. Available from: http://docplayer.net/287880-Good-occupational-health-practice.html

9. Sng J, Lee SM, Koh D. Bridging the gap between occupational medicine and family medicine. Ann Acad Med Singapore. 2008;37(2):158-61.

10. Bondy SC. The future of occupational medicine. Occup Med Health Aff. 2015;3(3):1000e109.

11. Lucas R, Benavides FG, editors. Trabalho e saúde em Portugal, 2016. Porto: Instituto de Saúde Pública da Universidade do Porto; 2016. ISBN 9789899886797

\section{CONFLITOS DE INTERESSE}

A autora declara não ter qualquer conflito de interesses.

\section{ENDEREÇO PARA CORRESPONDÊNCIA}

avelinamoniz@gmail.com

Artigo redigido ao abrigo do acordo ortográfico anterior a 1990. 